\title{
CHRONIC HYPOXIA INDUCES ADAPTIVE METABOLIC CHANGES IN NEONATAL MYOCARDIUM
}

Mark D. Plunkett, MD $^{\mathrm{a}}$

Paul J. Hendry, MD ${ }^{a}$

Mark P. Anstadt, MD $^{\mathrm{a}}$

Enrico M. Camporesi, MD ${ }^{\mathrm{b}}$

Mary T. Amato, $\mathrm{MD}^{\mathrm{a}}$

James D. St. Louis, MD $^{\mathrm{a}}$

James E. Lowe, MD ${ }^{\mathrm{a}}$
The effect of chronic hypoxia on neonatal myocardial metabolism remains undefined. With a new neonatal piglet model, we determined changes in myocardial metabolism during global ischemia after chronic hypoxia. Fiveday-old piglets $(N=30)$ were randomly assigned to two groups and exposed to an atmosphere of $8 \%$ oxygen or to room air for 28 days before they were killed. Left ventricular myocardium was then analyzed at control and at 15-minute intervals during 60 minutes of global normothermic ischemia to determine high-energy phosphate levels, glycogen stores, and lactate accumulation. Time to peak ischemic myocardial contracture was measured with intramyocardial needle-tipped Millar catheters as a marker of the onset of irreversible ischemic injury. Results showed an initially greater level of myocardial adenosine triphosphate in the hypoxic group (27 \pm 1.2 vs $19 \pm 1.8 \mu \mathrm{mol} / \mathrm{gm} \mathrm{dry} \mathrm{wt,} p=$ 0.001 ) and a delay in adenosine triphosphate depletion during 60 minutes of global ischemia compared with the control group. Initial energy charge ratios ( $1 / 2$ adenosine diphosphate + adenosine triphosphate/adenosine monophosphate + adenosine diphosphate + adenosine triphosphate) were also greater in the hypoxic group $(0.96 \pm 0.01$ vs $0.81 \pm 0.04, p=0.01)$ and remained so throughout global ischemia. Initial glycogen stores were greater in the hypoxic group $(273 \pm 13.3$ vs $215 \pm 14.7 \mu \mathrm{mol} / \mathrm{gm}$ dry weight, $p=0.02)$ when compared with the control group. Lactate levels in the hypoxic group were initially higher $(19.1 \pm 6.4$ vs $8.9 \pm 3.1 \mu \mathrm{mol} / \mathrm{gm}$ dry weight, $p=0.001)$ compared with control levels and remained elevated throughout 60 minutes of ischemia. Time to peak ischemic contracture was prolonged in the hypoxic group (69.5 \pm 1.8 vs $48.9 \pm 1.4$ minutes, $p=0.001)$ compared with the controls group. These data show that chronic hypoxia results in significant myocardial metabolic adaptive changes, which in turn result in an improved tolerance to severe normothermic ischemia. These beneficial effects are associated with elevated baseline glycogen storage levels and an accelerated rate of anaerobic glycolysis during ischemia. (J Thorac Cardiovasc Surg 1996;112:8-13)
$\mathrm{C}$ yanotic congenital heart defects result in chronic hypoxia in the neonate until operative correction is achieved. The effects of chronic hypoxia on neonatal myocardial metabolism have not been well defined. Previous studies involving cyanotic animal

From the Departments of Surgery ${ }^{\mathrm{a}}$ and Anesthesia, ${ }^{\mathrm{b}}$ Duke University Medical Center, Durham, N.C.

Supported in part by National Research Service Award NIH HL07819-02, SCOR HL-17670, and the Harold and Linda Plemmons Cardiac Surgical Research Foundation.

Received for publication June 14, 1995; revisions requested Sept. 22, 1995; revisions received Dec. 26, 1995; accepted for publication Dec. 26, 1995.

Address for reprints: James E. Lowe, MD, Department of Surgery, Box 3954, Duke University Medical Center, Durham, NC 27710.

Copyright (C) 1996 by Mosby-Year Book, Inc.

$0022-5223 / 96 \$ 5.00+0 \quad \mathbf{1 2 / 1 / 7 1 4 5 4}$ models and clinical studies in infants with cyanotic lesions were complicated by changes in cardiac anatomy and physiology that induced other changes in myocardial function and metabolism concurrently with cyanosis. Most previous experimental investigations used adult animal models and were characterized by short durations or variable levels of hypoxia. ${ }^{1-9}$ This study was intended to investigate the primary metabolic effects of chronic hypoxia on otherwise normally developed neonatal myocardium. To accomplish this, a new animal model of induced chronic hypoxia in the newborn piglet without surgical alterations was developed. This method accurately controls the degree of hypoxia to which each animal is exposed. Use of this model allows investigation of hypoxia as a controlled variable, without the confounding effects of abnormal anatomy and physiology. 


\section{Material and methods}

Thirty neonatal (5-day-old) piglets were randomly assigned to two groups. The first group, raised in a room-air environment, served as the control group. The second group, raised in a specially designed stainless-steel chamber and maintained in an atmosphere of $8 \%$ oxygen and balanced nitrogen, served as the experimental hypoxic group (Fig. 1). Air flow through the chambers of $15 \mathrm{~L} / \mathrm{min}$ kept the carbon dioxide content of both atmospheres at less than $1 \%$ at all times. Oxygen (Beckman E.C. Oxygen Analyzer; Beckman Instruments, Inc., Fullerton, Calif.) and carbon dioxide levels were continuously monitored, as were temperature and humidity. All animals were raised for 28 days with identical feeding schedules. The hypoxic animals were exposed to room air conditions for a mean of $25.5 \pm 2.5$ minutes during each 24 -hour period, to allow cleaning and maintenance of the chambers. Weekly measurements of weights and capillary tube venous hematocrits were recorded for each animal. Arterial saturations were measured with pulse oximetry (Nellcor Pulse Oximeter; Nellcor, Inc., Hayward, Calif.). The oximeter probe was fitted to the proximal tail of each animal, and arterial saturations were recorded in a standard manner.

The piglet is an ideal animal for this model because of its developmental maturity and its ability to eat from a bowl several days after birth. All animals received humane care in compliance with the "Principles of Laboratory Animal Care" formulated by the National Society for Medical Research and the "Guide for the Care and Use of Laboratory Animals" prepared by the Institute of Laboratory Animal Resources and published by the National Institutes of Health (NIH Publication No. 86-23, revised 1985). Survival did not differ significantly between the groups. Three control animals and three hypoxic animals did not survive to completion of the study. All six of these animals died within the first 2 weeks of the study. Post mortem examinations revealed pneumonitis in three, small-bowel intussuception in one, and patent ductus arteriosus in another. One animal had a seizure disorder of uncertain etiology and died 1 week after birth.

After 4 weeks, the animals were sedated with intramuscular ketamine $(20 \mathrm{mg} / \mathrm{kg})$, anesthetized with intravenous pentobarbital $(20 \mathrm{mg} / \mathrm{kg})$, and then intubated and ventilated mechanically (Harvard Respirator, model 607; Harvard Apparatus, Inc., South Natick, Mass.). The inspired oxygen used for ventilation was the same in each case as the gas mixture in which that animal was raised. A median sternotomy was performed, and pressure measurements were obtained from all chambers of the heart. Pressure measurements were also obtained from the main pulmonary artery and the ascending aorta. These hemodynamic measurements were recorded with an on-line strip-chart recorder and Millar pressure catheters.

A transmural drill biopsy sample was obtained from the left ventricular free wall and rapidly frozen for subsequent determinations of lactate, glycogen, and high-energy phosphate levels. The hearts were then rapidly excised and left ventricular free walls were dissected from the specimens. The left ventricular free walls were divided into halves, wrapped in plastic bags, and placed in a $38^{\circ} \mathrm{C}$ water bath for 60 minutes of normothermic ischemia. Half of the samples were instrumented with Mikro-Tip 5F Millar needle pres-

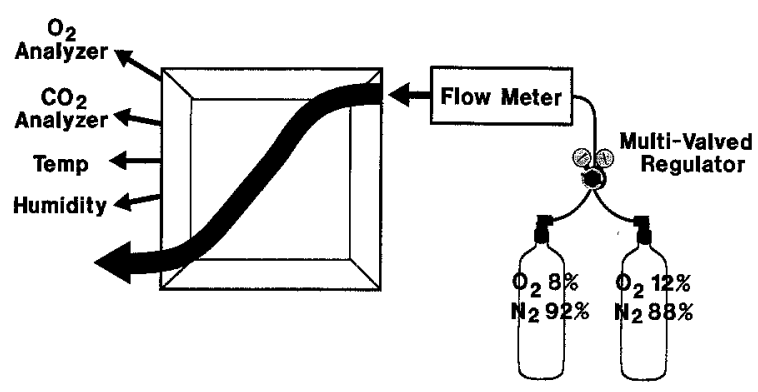

$15 \mathrm{~L} /$ Min Constant Flow

Fig. 1. Chamber used to induce atmospheric hypoxia. Flow of premixed air at $15 \mathrm{~L} / \mathrm{m}$ maintains constant atmosphere with minimal carbon dioxide accumulation.

sure transducers (Millar Instruments, Inc., Houston, Texas) and maintained in the water bath after instrumentation. On-line measurements of developing intramyocardial pressure were recorded during normothermic global ischemia. Time to peak ischemic contracture was defined as the point at which the highest myocardial pressure was recorded. The remaining sections of myocardium underwent transmural biopsy sampling at 15 -minute intervals. The biopsy samples were obtained from the more central portion of each piece of tissue, to reduce the effect of exposure to room-air conditions of the more superficial tissue. These biopsy samples were rapidly frozen and stored for later determinations of high-energy phosphate and lactate levels with using high-performance liquid chromatography. ${ }^{10}$ All collected biopsy samples were stored in a freeze-dry system (LyphLock; Labconco, Kansas City, Mo.) for 48 hours. Regional tissue samples were weighed on a minibalance (model 9500; Cohn Instruments, Cerritus, Calif.).

Statistical analysis. Measurements of regional depletion of myocardial high-energy phosphates (mean \pm standard error of the mean [SEM]) and lactate accumulation (mean $\pm \mathrm{SEM}$ ) during normothermic ischemia were compared between control and hypoxic groups by means of analysis of variance with repeated measures across time. Regional myocardial time to peak ischemic contracture, initial high-energy phosphate levels, initial glycogen stores, and hemodynamic measurements (mean \pm SEM) were compared with a nonpaired Student's $t$ test. An $\alpha$ level of 0.05 was used to determine statistical significance in all analyses.

\section{Results}

Monitored physiologic data. Arterial oxygen saturations were measured with pulse oximetry in all animals. The mean arterial saturations in the hypoxic group $(70.3 \% \pm 1.1 \%$ vs $98.1 \% \pm 0.24 \%, p=0.0001)$ were significantly reduced compared with those in the control group. Arterial blood gas analyses confirmed these measurements at the completion of the study, with the hypoxic group having a reduced mean partial pressure of arterial oxygen $(45.6 \pm 1.3$ vs $97.3 \pm 1.9$ $\mathrm{mm} \mathrm{Hg}$ ). Venous hematocrits were measured weekly 


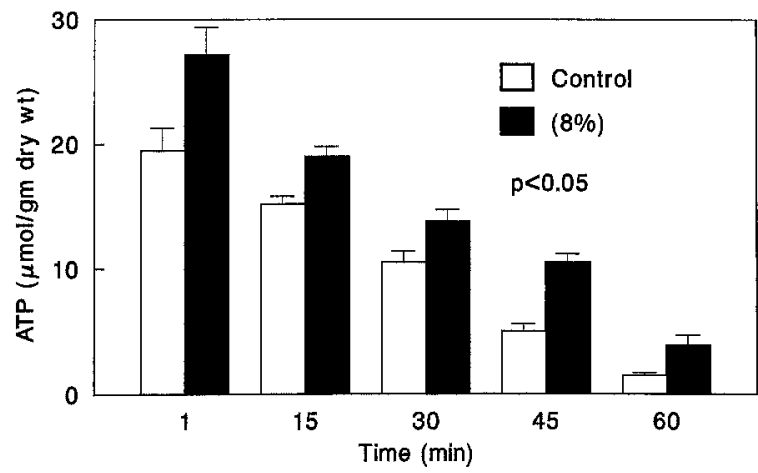

Fig. 2. Myocardial ATP levels measured at 15-minute intervals during normothermic global ischemia, hypoxic group (inspired oxygen fraction $8 \%$, black bars) vs control group (white bars). Data are mean \pm SEM. wt, Weight.

for all animals, and mean values in the hypoxic group rose steadily during the 4-week period. Final mean hematocrit values were significantly higher in the hypoxic group $(59.1 \% \pm 0.80 \%$ vs $36.2 \% \pm 0.94 \%$, $p=0.0001$ ) than in the control group. Total body weights, recorded weekly for all animals, revealed a reduced growth rate in all hypoxic animals ( $4250 \pm$ 207.6 vs $5525 \pm 219.4$ gm, $p=0.026$ ) compared with that in all control animals. Hemodynamic measurements were recorded for each animal before cardiac extirpation. Pulmonary artery and right ventricular pressures were elevated significantly in the hypoxic group, and mean pulmonary artery diastolic pressures ( $38.3 \pm 0.87$ vs $12.0 \pm 0.24 \mathrm{~mm} \mathrm{Hg}, p=0.0001)$ were also significantly greater than those in the control group. Significant right ventricular hypertrophy in the hypoxic group was demonstrated by greater right ventricular free wall weights $(15.8 \pm 0.9$ vs $8.6 \pm 0.6 \mathrm{gm}$, $p=0.002)$ than in the control group. Mean left ventricular free wall weights in the hypoxic group were found to be no different than in the control group. There was also no significant difference between groups in mean left ventricular pressure.

High-energy phosphate stores. Transmural biopsy samples of left ventricular myocardium were obtained from all piglets and analyzed with a highperformance liquid chromatography technique. ${ }^{10}$ Adenosine triphosphate (ATP) levels were initially elevated in the hypoxic group $(27 \pm 1.2$ vs $19 \pm 1.8$ $\mu \mathrm{mol} / \mathrm{gm}$ dry weight, $p=0.001)$ compared with the control group (Fig. 2). Initial energy charge ratios were from ATP, adenosine diphosphate (ADP), and adenosine monophosphate (AMP) as follows: calculated by $1 / 2$ ADP + ATP/AMP + ADP + ATP. These ratios paralleled the other findings $(0.96 \pm$ 0.01 vs $0.81 \pm 0.04, p=0.01$; Fig. 3 ).

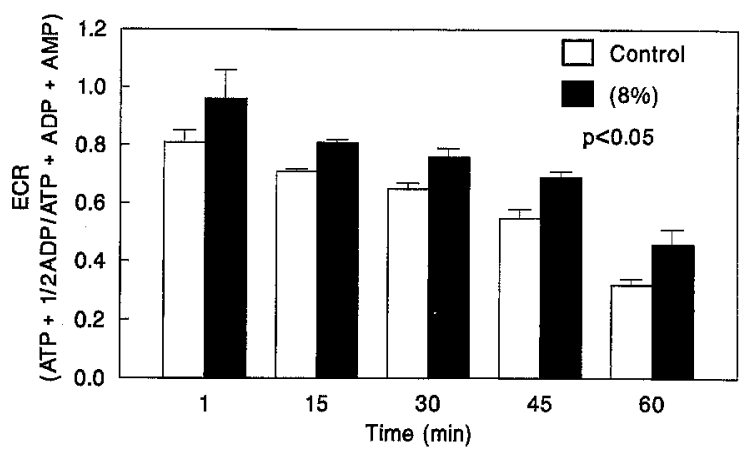

Fig. 3. Myocardial energy charge ratios (ECR) calculated from measurements of high-energy phosphate (ATP, ADP, and AMP) levels (ATP + 1/2 ADP/ATP + ADP + AMP) at 15-minute intervals of normothermic global ischemia, hypoxic group (inspired oxygen fraction $8 \%$, black bars) vs control group (white bars). Data are mean \pm SEM.

High-energy phosphate depletion during normothermic ischemia. The depletion of left ventricular myocardial ATP stores was measured at 15-minute intervals during 60 minutes of normothermic global ischemia. ATP depletion was consistently delayed in the hypoxic group compared with the control group, $p=0.01$ (Fig. 2). Energy charge ratios for the two groups again paralleled these findings $(p=0.03$; Fig. 3).

Time to peak ischemic contracture. Time to peak ischemic contracture of the left ventricular myocardium in the hypoxic animals $(69.5 \pm 1.8$ vs $48.9 \pm 1.4$ $\min , p=0.001$ ) was significantly prolonged compared with control values (Fig. 4). This finding was consistent with the delay in ATP and high-energy phosphate depletion found in all animals in the hypoxic group.

Glycogen stores. Myocardial glycogen stores measured in the left ventricular transmural biopsy samples obtained immediately after median sternotomy revealed higher initial glycogen stores in the hypoxic group ( $273 \pm 13.3$ vs $215 \pm 14.7 \mu \mathrm{mol} / \mathrm{gm}$ dry weight, $p=0.03$ ) than in the control group (Fig. 5).

Lactate accumulation during normothermic ischemia. Initial myocardial lactate levels were greater in the hypoxic group $(19.1 \pm 6.4$ vs $8.9 \pm 3.1 \mu \mathrm{mol} / \mathrm{gm}$ dry weight, $p=0.001$ ) than in the control group (Fig. 6). The accumulation of tissue lactate during 60 minutes of ischemia was also consistently greater in the hypoxic group until late ischemia ( $p=0.08$; Fig. 6).

\section{Discussion}

With a new piglet model, this study was designed to investigate the effects of chronic hypoxia on neonatal left ventricular myocardial metabolism. The piglet model used in this study allows hypoxia to 


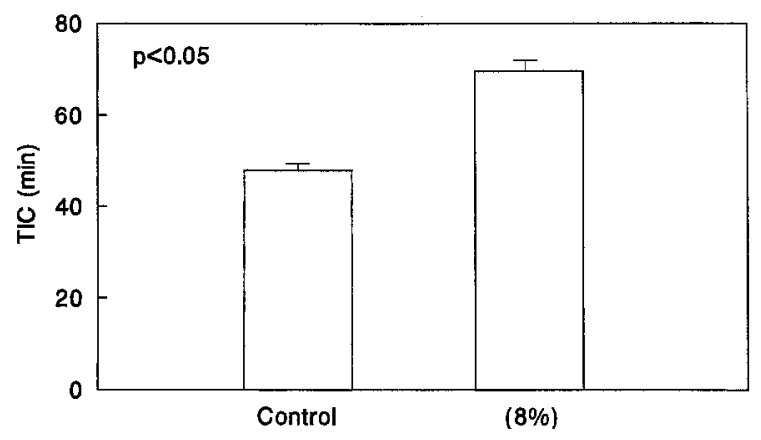

Fig. 4. Myocardial time to peak ischemic contracture (TIC) measured in minutes during normothermic global ischemia, hypoxic group (inspired oxygen fraction $8 \%$ ) vs control group.

be controlled as a variable without the introduction of initial anatomic or hemodynamic abnormalities. Only one (nonsurviving) piglet was found to have a patent ductus arteriosus at postmortem examination. This animal died several days after initial hypoxia. No other cardiac abnormalities were identified in the remaining animals. Findings from these studies of both metabolic and physiologic significance thus represent the direct effects of chronic hypoxia on normally developed left ventricular myocardium.

Previous studies confirmed the correlations among time to peak ischemic contracture and highenergy phosphate depletion and the onset of irreversible injury during myocardial ischemia. ${ }^{11}$ The method of measuring these parameters during in vitro normothermic global ischemia eliminates such confounding variables as collateral flow, wall tension, and electrophysiologic factors. Ultrastructural changes indicating reversible and irreversible cellular damage occur as myocardial contracture and highenergy phosphate depletion progress. ${ }^{12,13}$ These histologic markers are consistently observed on electron microscopy during maximal ischemic myocardial contracture. The data from this study show a greater production of high-energy phosphates in chronically hypoxic myocardium and a persistent delay in the depletion of these energy stores during normothermic global ischemia. This delay in depletion, associated with a prolongation of time to peak ischemic contracture, indicates an adaptive increase in myocardial tolerance to global ischemia.

Compared with that of adults, fetal myocardium uses glycogen stores and glucose as a greater energy source. It has been estimated that fetal myocardium obtains at least one third of its cellular energy from glycolysis and glucose metabolism. ${ }^{14}$ As growth and

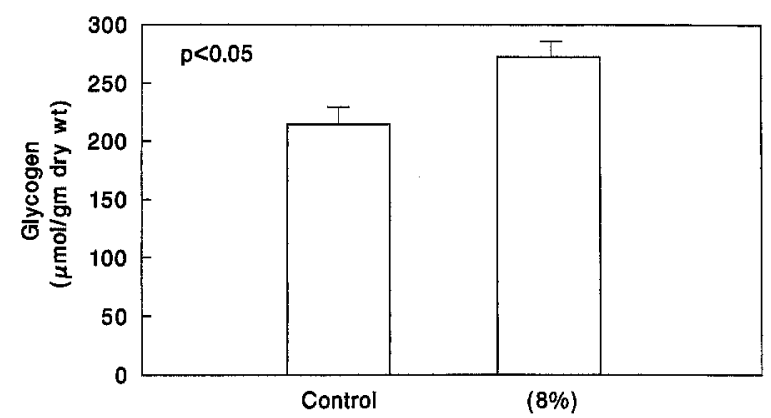

Fig. 5. Myocardial glycogen stores measured immediately before the onset of normothermic global ischemia, hypoxic group (inspired oxygen fraction $8 \%$ ) vs control group. Data are mean \pm SEM. $w t$, Weight.

development continue in the neonatal period, myocardial metabolism relies predominantly on the oxidation of long-chain fatty acids as a primary energy source. ${ }^{15-17}$ Under normal physiologic conditions, an increased rate of glycolysis is seen in response to acute cellular hypoxia. This metabolic change is related to an increase in the intracellular enzyme activity of phosphofructokinase, which increases cellular glycolysis in response to high-energy phosphate depletion. ${ }^{18}$ Previous metabolic studies on chronically hypoxic myocardium demonstrated increases in glucose uptake, glycogen storage, and glycolysis, as well as increases in the efficiency of enzymes controlling oxidative phosphorylation. ${ }^{19-23}$ These findings suggest that metabolic changes in myocytes adapting to chronic hypoxia serve to increase myocardial glycogen stores and promote the use of both aerobic and anaerobic glycolysis for energy production. Recent studies have demonstrated that the myocardium of rats in utero is far more resistant to ischemia than that of neonatal rats. The myocardium of neonatal rats is in turn more resistant to ischemia than that of 1 -week-old rats. ${ }^{24}$ This indicates that metabolic adaptations of the developing fetal myocardium to in utero hypoxia induces greater myocardial resistence to ischemia. ${ }^{25}$ These adaptations are characterized by increased highenergy phosphate levels, increased glycogen storage, and higher rates of glycolysis. ${ }^{16,26}$

Glucose transport is carrier mediated and accelerated by both insulin and epinephrine. Under the stress of hypoxia, both insulin and epinephrine levels remain elevated in the neonatal piglet. Glucose uptake and metabolism are also increased by the activity of hexokinase, which is known to be stimulated by ATP depletion. ${ }^{18}$ Glucose uptake is therefore accelerated in the acutely hypoxic myocardium, increasing its avail- 


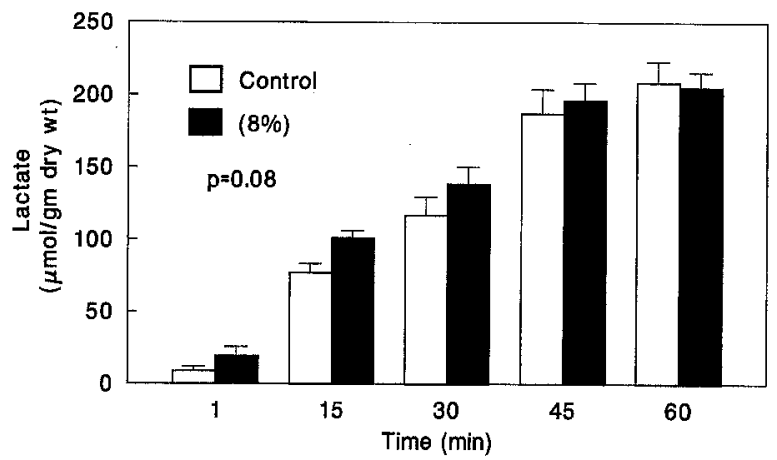

Fig. 6. Myocardial lactate levels measured at 15-minute intervals during normothermic global ischemia, hypoxic group (inspired oxygen fraction $8 \%$, black bars) vs control group (white bars). Data are mean \pm SEM.

ability for glycogen storage as well as immediate use in glycolysis. ${ }^{27,28}$ This same adaptation has been seen in fetal myocardium ${ }^{29}$ and in the myocardium of animals adapting to high altitudes. ${ }^{30}$

Cellular enzyme systems involved in myocardial high-energy phosphate production increase their activity and efficiency during adaptation to chronic hypoxia. ${ }^{21,22,31-33}$ It is known that the activity of the mitochondrial enzymes and the capacity of the mitochondrial system per unit of tissue is increased during adaptation to altitude hypoxia. ${ }^{34,35}$ All of these adaptations serve to increase myocardial highenergy phosphate production and increase tolerance to subsequent ischemia.

In summary, prolonged hypoxia of normally developed left ventricular myocardium leads to a greater capacity for glucose uptake and glycogen storage, in turn leading to greater use of aerobic and anaerobic glycolysis for ATP production. In an attempt to meet cellular demands under chronically hypoxic conditions, the enzymes involved in glycogen storage, aerobic and anaerobic glycolysis, and oxidative phosphorylation must achieve greater efficiency in producing and maintaining cellular ATP levels. Consequently, at any given time in cellular metabolism, greater glycogen stores are present and higher lactate levels are found than in nonhypoxic myocardium (Fig. 7). During subsequent hypoxia and ischemia, these metabolic adaptations allow a longer survival of cellular metabolism and a prolonged time to ischemic contracture. The same metabolic characteristics and increased tolerance to ischemia were recently described in both fetal myocardium and myocardium exposed to chronic altitude hypoxia. No conclusions can be drawn concerning the contractile function of the myocardium as a

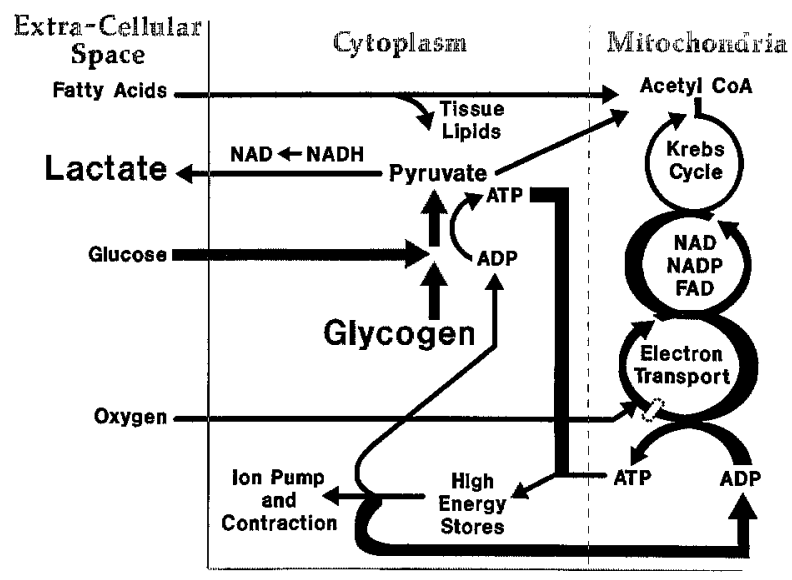

Fig. 7. Schematic representation of myocardial metabolism showing adaptative changes after chronic hypoxia. Increased glycogen stores and lactate accumulation (bold type) indicate a greater use of the glycolytic pathway for ATP production in response to prolonged hypoxic conditions. Acetyl $C O A$, acetyl coenzyme A; $N A D$, nicotinamide adenine dinucleotide; $N A D H$, reduced nicotinamide adenine dinucleotide phosphate; $F A D$, flavin adenine dinucleotide.

working syncitium because each sample in this study was isolated and subjected to ex vivo global ischemia. The metabolism and mechanical function of in vivo myocardium, in contrast, are affected by collateral perfusion, changes in wall tension, and electrophysiologic factors. These differences may alter metabolism and mechanical function differently than the adaptations found in this study.

Paradoxically, both laboratory and clinical experiences to date have supported the concept of a relative intolerance of the myocardium of cyanotic neonates to operative ischemia. ${ }^{4,7,8}$ Poor functional recovery after operative intervention in these neonates suggests a reduced tolerance to ischemia in chronically hypoxic myocardium. These observations were made in settings in which anatomic lesions and their hemodynamic and physiologic consequences complicated the assessment of chronic hypoxia. Because many clinical and laboratory investigations have demonstrated reduced functional tolerance to ischemia in infants with cyanotic congenital lesions, it is reasonable to conclude that the consequences of altered anatomy and physiology (e.g., myocardial hypertrophy or dilatation) resulting from pressure and volume overload play a detrimental role in the myocardium's tolerance to operative ischemia. Acute changes in hemodynamics as a result of operative reconstruction and methods of myocardial protection may also be factors in determining postoperative myocardial function. In 
fact, the consequences of these other variables may often override any favorable metabolic adaptations induced by chronic hypoxia. Further studies on myocardial function with this new animal model are necessary to further clarify these questions.

This study demonstrated adaptive changes in the neonatal left ventricular myocardium in response to prolonged hypoxia. It is uncertain whether these findings would persist during even longer periods of hypoxia. It also remains to be seen whether these adaptations would reverse or persist after the return to normal oxygenation.

\section{REFERENCES}

1. Fujiwara T, Kurtts T, Anderson W, Heinle J, Mayer JE. Myocardial protection in cyanotic neonatal lambs. J Thorac Cardiovasc Surg 1988;96:700-10.

2. Rudolph W. Myocardial metabolism in cyanotic congenital heart disease. Cardiology 1972;56:209-15.

3. Scheuer J, Shaver JA, Kroetz FW, Leonard JJ. Myocardial metabolism in cyanotic congenital heart disease. Cardiology 1970;55:193-210.

4. Silverman NA, Kohler J, Levitsky S, Pavel DG, Fang RB, Feinberg H. Chronic hypoxemia depresses global ventricular function and predisposes to the depletion of high energy phosphates during cardioplegic arrest: implications for surgical repair of cyanotic congenital heart defects. Ann Thorac Surg 1984;37:304-8.

5. Friedli B, Haenni B, Moret P, Opie LH. Myocardial metabolism in cyanotic congenital heart disease studied by arteriovenous differences of lactate, phosphate, and potassium at rest and during atrial pacing. Circulation 1977;55:647-52.

6. Lupinetti FM, Wareing TH, Huddleston CB, Collins JC, Boucek RJ, Bender HW Jr, et al. Pathophysiology of chronic cyanosis in a canine model. J Thorac Cardiovasc Surg 1985;90:291-6.

7. Graham TP, Erath HG, Boucek RJ, Boerth RC. Left ventricular function in cyanotic congenital heart disease. Am J Cardiol 1980;45:1231-6.

8. Graham TP Jr, Erath HG Jr, Buckspan GS, Fisher RD. Myocardial anaerobic metabolism during isoprenaline infusion in a cyanotic animal model: possible cause of myocardial dysfunction in cyanotic congenital heart disease. Cardiovasc Res 1979;13:401-6.

9. Visner MS, Arentzen CE, Ring WS, Anderson RW. Left ventricular dynamic geometry and diastolic mechanics in a model of chronic cyanosis and right ventricular presure overload. J Thorac Cardiovase Surg 1981;81:347-57.

10. Hull-Ryde EA, Lewis WR, Veronee CD, Lowe JE. Simple step gradient elution of the major high energy compounds and their catabolites in cardiac muscle using high-performance liquid chromatography. J Chromatogr 1986;377:165-74.

11. Lowe JE, Jennings RB, Reimer KA. Cardiac rigor mortis in dogs. J Mol Cell Cardiol 1979;11:1017-31.

12. Jennings RB, Ganote CE. Structural changes in myocardium during acute ischemia. Circ Res 1974;34(Suppl 3):156-72.

13. Jennings RB, Hawkins HK, Lowe JE. Relation between high energy phosphate and lethal injury in myocardial ischemia in the dog. Am J Pathol 1978;92:187-214.

14. Riva E, Hearse DJ. The developing myocardium. New York: Futura Publishing, 1991:1-20.
15. Warshaw JB. Cellular energy metabolism during fetal development. IV. Fatty acid activation, acyl transfer and fatty acid oxidation during development of the chick and rat. Dev Biol 1972;28:537-44.

16. Dawes GS, Mott JC, Shelley HJ. The importance of cardiac glycogen for the maintenance of life in fetal lambs and new-born animals during anoxia. J Physiol 1959;146:516-38.

17. Shelley HJ. Glycogen reserves and their changes at birth and in anoxia. Br Med Bull 1961;17:137-43.

18. Katz AM. Physiology of the heart. 2nd ed. New York: Raven Press, 1992:74-97.

19. Hammond GL, Nadal-Ginard B, Talner NS, Markert CL. Myocardial LDH isozyme distribution in the ischemic and hypoxic heart. Circulation 1976;53:637-43.

20. Warshaw JB, Terry ML. Cellular energy metabolism during fetal development: fatty acid oxidation by the developing heart. J Cell Biol 1970;44:354-60.

21. Reynafarje B. Effect of chronic hypoxia on the kinetics of energy transformation in heart mitochondria. Cardiology 1971;56:206-8.

22. Moret P, Covarrubias E, Coudert J, Duchosal F. Cardiocirculatory adaptation to chronic hypoxia. Acta Cardiol 1972; 27:483-503.

23. Mela L, Goodwin CW, Miller LD. In vivo control of mitochondrial enzyme concentrations and activity by oxygen. Am J Physiol 1976;231:1811-6.

24. Hoerter J. Changes in the sensitivity to hypoxia and glucose deprivation in the isolated perfused rabbit heart during perinatal development. Pfluegers Arch 1976;363:1-6.

25. Moore KL. The developing human. 3rd ed. Philadelphia: WB Saunders, 1982:298-343.

26. Hoerter JA, Opie LH. Perinatal changes in glycolytic function in response to hypoxia in the incubated or perfused rat heart. Biol Neonate 1978;33:144-61.

27. Purshottam T, Kaveeshwar U, Brahmachari HD. Changes in tissue glycogen stores of rats under acute and chronic hypoxia and their relationship to hypoxic tolerance. Aviat Space Environ Med 1977;48:351-5.

28. Hance AJ, Robin ED, Simon LM, Alexander S, Herzenberg LA, Theodore J. Regulation of glycolytic activity during chronic hypoxia by changes in pyruvate kinase content. J Clin Invest 1980;66:1258-64

29. Young HH, Shimizu T, Nishioka K, Nakanishi T, Jarmakani JM. Effect of hypoxia and reoxygenation on mitochondrial function in neonatal myocardium. Am J Physiol 1989;245: H998-1006.

30. Tappan DV, Reynagarje BD, Potter VR, Hurtado A. Alterations in enzyme and metabolites resulting from adaption to low oxygen tensions. Am J of Physiol 1957;190:93-8.

31. Grover RF, Alexander JK. Cardiac performance and the coronary circulation of man in chronic hypoxia. Cardiology 1971;56:197-206.

32. Poupa O. Anoxic tolerance of the heart muscle in different types of hypoxia. Cardiology 1972;56:188-96.

33. Harris P, Castillo Y, Gibson K, Heath D, Arias-Stella J: Succinic and lactic dehydrogenase activity in myocardial homogenates from animals at high and low altitudes. J Mol Cell Cardiol 1970;1:189-93.

34. Reynafarje B. Myoglobin content and enzymatic activity of muscle and altitude adaptation. J Appl Physiol 1962;17:301-5.

35. Meerson FZ. Role of the synthesis of nucleic acids and proteins in the adaptation of the organism to altitude hypoxia. Cardiology 1972;56:173-87. 